\title{
Assessment of the protective effect of PMMA on water immersion ageing of flame retarded PLA/PMMA blends
}

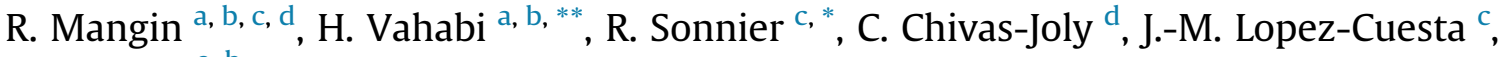 \\ M. Cochez ${ }^{\text {a, b }}$ \\ a Université de Lorraine, CentraleSupélec, LMOPS, F-57000, Metz, France \\ b Laboratoire Matériaux Optiques, Photoniques et Systèmes, CentraleSupélec, Université Paris-Saclay, 57070, Metz, France \\ ${ }^{\mathrm{c}}$ Polymers Composites and Hybrids (PCH) IMT Mines d'Alès, 30100, Alès, France \\ d Laboratoire National de Métrologie et d'Essais (LNE), 78197, Trappes Cedex, France
}

\section{A B S T R A C T}

The incorporation of PMMA into phosphorus-containing flame retarded PLA was assessed as a possible strategy to reduce the sensitivity of the material to ageing in water at $70^{\circ} \mathrm{C}$. PLA and PMMA are miscible and the unique glass transition temperature can be easily controlled by a proper amount of PMMA according to Gordon-Taylor equation. Water penetration as well as phosphorus release was reduced when incorporated PMMA amount increased. Consequently, the ability to form char and the fire performances measured in cone calorimeter were further preserved. Nevertheless, an efficient protective effect was only observed when PMMA incorporation allows the glass transition temperature in the blend to increase above the ageing temperature. This is achieved for a weight ratio PMMA/PLA no lower than 1.

Keywords:

PLA

PMMA blends

Ageing

Flame retardancy

Phosphorus flame retardants

\section{Introduction}

Due to environmental concerns, nowadays a huge effort is dedicated to the substitution of oil-based materials (polymers, reinforcements, and additives) by biobased ones. Poly(lactic acid) (PLA) is the most investigated biobased polymer. Despite its good Young's modulus and tensile strength, it has some drawbacks, especially its sensitivity to hydrolysis as well as its high flammability.

Therefore, an important number of research works has been devoted to the development of flame retardant systems for PLA [1-3]. Different systems have been proposed, including phosphorus-based ones. It has been shown that the combination of a phosphorus additive acting as charring promoter (as ammonium polyphosphate (APP)) and a mineral filler at nanometric scale, reinforcing the barrier effect during combustion, is very efficient [4-6].

\footnotetext{
* Corresponding author.

** Corresponding author. Université de Lorraine, CentraleSupélec, LMOPS, F57000 Metz, France.

E-mail address: rodolphe.sonnier@mines-ales.fr (R. Sonnier).
}

The fire performance should be preserved during the whole service life of a material. However, this requirement is not methodically assessed for many applications. Indeed, there are still few studies about the influence of ageing on flame retardancy, even if some efforts have been devoted to this issue in the last years. Ageing sources are multiple, including temperature, UV, relative humidity, water immersion, abrasion, cleaning using various solvents, electric shocks, gamma radiations and so on. Pioneering works have been carried out by Clough on flame retardant (FR) cables submitted to thermal and gamma radiation ageing $[7,8]$.

Jimenez et al. have shown APP-based intumescent systems become inefficient in epoxy-based intumescent coatings after immersion in salt water due to different phenomena, the main one being the removal of phosphorus in the ageing condition [9]. Braun et al. have compared the resistance to weathering of different FR systems in different polymers and have concluded that this resistance depends on the FR mode-of-action [10]. Thus, there is no general tendency and the fire performances can be altered, constant or even improved depending on the ageing conditions, the FR system and the polymer. Vahabi et al. reviewed these aspects [11].

Lesaffre et al. investigated the influence of ageing at $50{ }^{\circ} \mathrm{C}$ and $75 \%$ of relative humidity on PLA flame retarded with melamine 
polyphosphate and APP. In one formulation, organomodified montmorillonite was added [12]). Surprisingly, the flame retardancy was improved during ageing according to the results obtained at Limiting Oxygen Index (LOI) and mass loss calorimetry tests. The authors explained such observations by two main phenomena: the hydrolysis of PLA (enhanced by FR) reduced the viscosity and enhanced the so-called "runaway effect". Moreover, the decrease in molecular weight allows the exsudation of APP, which is concentrated at the surface, where it can act effectively to promote charring. In a further work, the same team extended these observations to various ageing conditions combining temperature, relative humidity, and UV exposure [13].

Even if in these previous works the flame retardancy of FR PLA was improved, hydrolysis of PLA is observed (with in some cases, a complete degradation of the material) as well as exsudation of APP which could be easily removed, especially in the case of immersion. Various strategies can be considered to slow down these phenomena. One is to deposit a hydrophobic coating on the material. This coating may be multifunctional combining water resistance and flame retardancy [14]. A second strategy is the encapsulation of APP, which does not prevent the hydrolysis of PLA but protects APP from the contact with water $[15,16]$. A third one is to modify the matrix by incorporating an additive in bulk to limit the water penetration.

In a previous work, we have added PMMA into a PLA flame retarded with sepiolite and APP subjected to ageing in water at $70{ }^{\circ} \mathrm{C}$ [17]. The PMMA/PLA weight ratio was set at 1 . The objective was to assess the influence of PMMA in order to limit the water penetration and the removal of phosphorus and consequently to maintain a high flame retardancy performances. In the present study, our investigations were extended to other PMMA/PLA ratio in order to identify a critical PMMA content allowing maintaining both fire performances and high biobased fraction in the material. First, the miscibility of PMMA/PLA blends was investigated using DSC analysis. Then, phosphorus release and mass loss during ageing were estimated. Thermal degradation and fire behavior before and after ageing were also analyzed and compared using thermogravimetric analysis (TGA) and cone calorimeter.

\section{Experimental}

PLA was supplied by NatureWorks (Ingeo 3251D, $\approx 1.4 \%$ D-isomer). PMMA was supplied by Arkema (Altuglas V825T). Ammonium polyphosphate was given by Clariant (Exolit AP 423, particle size $\approx 9 \mu \mathrm{m}$, specific surface area $1.1 \mathrm{~m}^{2} / \mathrm{g}$ ). Sepiolite, a natural nanometric phyllosilicate $\left(\mathrm{Mg}_{4} \mathrm{Si}_{6} \mathrm{O}_{15}(\mathrm{OH})_{2} \cdot 6 \mathrm{H}_{2} \mathrm{O}\right.$, specific surface area $=320 \mathrm{~g} / \mathrm{m}^{2}$ ) produced by Tolsa (Pangel S9) was supplied by Lavollée S.A.

Flame-retarded polymers were compounded and pelletized using a twin screw extruder (Clextral BC 21, France) with following parameters: $\mathrm{L}=1200 \mathrm{~mm}, \mathrm{~L} / \mathrm{D}=48$, screw speed $=200 \mathrm{rpm}$, melt zone temperature $=190-240{ }^{\circ} \mathrm{C}$ ). For all formulations, $15 \mathrm{wt} \%$ fillers were added. Neat polymers as well as neat PMMA/PLA blend were also prepared. Formulations are listed in Table 1. Polymers and fillers were dried in vacuum at $80{ }^{\circ} \mathrm{C}$ for at least $4 \mathrm{~h}$ before melt mixing. Specimens adapted for cone calorimeter tests $(100 \mathrm{x}$ $100 \times 4 \mathrm{~mm}^{3}$ ) were injection molded from the obtained pellets, after vacuum drying at $80{ }^{\circ} \mathrm{C}$ for at least $4 \mathrm{~h}$. All samples required for analysis were cut from these square sheets.

Accelerated ageing on square sheet samples were carried out using an autoclave, at $70{ }^{\circ} \mathrm{C}$, for 1,2 and 3 weeks. 9 samples ( 3 samples each week) were completely immersed into distilled water (8L). After 1 week of ageing, 3 samples were removed from the ageing media. Distilled water was then renewed in the autoclave with the last 6 samples. The same procedure was applied after the second and the third week of ageing.

All the initial sample masses $m_{0}$ were measured, prior to ageing. When samples were removed from the autoclave, water was firstly wiped off from the surface, and then sample masses $m_{w o}$ were quickly measured. Finally, samples were weighed after vacuum drying at $58{ }^{\circ} \mathrm{C}$ for $4 \mathrm{~h}$ to determine $\mathrm{m}_{\mathrm{dry}}$. The weight gain after ageing and before drying $\mathrm{W}_{\mathrm{a}}(\%)$, the water uptake $\mathrm{W}_{\mathrm{up}}(\%)$ and the final weight gain (after ageing and drying) $\mathrm{W}_{\mathrm{f}}(\%)$ were determined following equations (1)-(3), respectively.

$\mathrm{W}_{a}=\frac{m_{w o}-m_{0}}{m_{0}} \times 100$

$\mathrm{W}_{u p}=\frac{m_{w o}-m_{d r y}}{m_{w 0}} \times 100$

$\mathrm{W}_{f}=\frac{m_{d r y}-m_{0}}{m_{0}} \times 100$

TGA was performed on a Setaram Labsys Evo (France) apparatus. The same procedure was applied for all experiments: samples of about $20 \mathrm{mg}$ were placed into alumina crucibles, and submitted to a temperature ranging from 35 to $1000^{\circ} \mathrm{C}$, at a heating rate of $10^{\circ} \mathrm{C} /$ min, under a nitrogen flow of $50 \mathrm{~mL} / \mathrm{min}$. Unaged and aged samples were tested.

Differencial scanning calorimetry (DSC) analyses were carried out on unfilled extruded blends and pure polymers using a DSC Netzsch 200 F3 Maia, Germany. Samples of around $5 \mathrm{mg}$ were sealed in aluminium pan. They were heated up to $200{ }^{\circ} \mathrm{C}$ with a scan rate of $10{ }^{\circ} \mathrm{C} / \mathrm{min}$, under nitrogen flow (50 mL/min). A first heating ramp was carried out, followed by a cooling step $\left(20^{\circ} \mathrm{C} /\right.$ min) and a second heating ramp. Since PMMA is amorphous, the crystallization phenomenon observed was assigned to PLA. The

Table 1

List of studied materials.

\begin{tabular}{|c|c|c|c|c|}
\hline Sample code & PMMA (wt\%) & PLA (wt\%) & APP (wt\%) & Sepiolite (wt\%) \\
\hline PMMA & 100 & 0 & 0 & 0 \\
\hline PLA & 0 & 100 & 0 & 0 \\
\hline PMMA/PLA 75/25 & 75 & 25 & 0 & 0 \\
\hline PMMA/PLA 50/50 & 50 & 50 & 0 & 0 \\
\hline PMMA/PLA 25/75 & 25 & 75 & 0 & 0 \\
\hline PMMA/PLA $15 / 85^{\mathrm{a}}$ & 15 & 85 & 0 & 0 \\
\hline PMMA/APP/S9 & 85 & 0 & 10 & 5 \\
\hline PMMA/PLA/APP/S9 50/50 & 42.5 & 42.5 & 10 & 5 \\
\hline PMMA/PLA/APP/S9 25/75 & 21.25 & 63.75 & 10 & 5 \\
\hline PMMA/PLA/APP/S9 15/85 & 12.75 & 72.25 & 10 & 5 \\
\hline PLA/APP/S9 & 0 & 85 & 10 & 5 \\
\hline
\end{tabular}

\footnotetext{
${ }^{\text {a }}$ Only for DSC analyses.
} 
crystallinity of PLA in the unfilled PMMA/PLA blend was calculated using equation (4):

$\chi_{c}=\frac{\Delta H_{m}-\Delta H_{c c}}{\Delta H_{m}^{0}} \times \frac{100}{w_{P L A}}$

where $\Delta H_{m}(J / g)$ is the measured melting enthalpy, $\Delta H^{0} \mathrm{~m}(\mathrm{~J} / \mathrm{g})$ is the melting enthalpy of PLA in its complete crystalline state $(93 \mathrm{~J} / \mathrm{g}$ ) [18], $\Delta \mathrm{H}_{\mathrm{cc}}(\mathrm{J} / \mathrm{g})$ is the measured cold crystallization enthalpy and WPLA is the weight fraction of PLA.

Inductively coupled plasma - atomic emission spectroscopy (ICP-AES) analyses (HORIBA Jobin Yvon, Activa M) were performed to determine the phosphorus content in the sample before and after ageing. Samples were dissolved in an acid solution (nitric/ sulfuric acid).

The molecular weights $M_{n}$ and $M_{w}$ and the polydispersity index PD of unaged and aged samples were determined using gel permeation chromatography (Varian ProStar model 210, US) equipped with a RI detector. Two PLgel $5 \mu \mathrm{m}$ Resipore were used at $70{ }^{\circ} \mathrm{C}$, calibrated with PMMA standards. Samples were initially dissolved in DMF (10 $\mathrm{mg} / \mathrm{ml})$ and then eluted. The measurements were carried out with a constant flow rate of $0.8 \mathrm{ml} / \mathrm{min}$.

The flammability properties of formulations were evaluated using a cone calorimeter device (FTT, UK and Fire, EU according to the ISO 5660-1 standard). All samples were dried under vacuum during at least $6 \mathrm{~h}$ before experiments. Sheets of $100 \times 100 \times 4 \mathrm{~mm}^{3}$ were exposed to a radiant cone with a heat flux of $50 \mathrm{~kW} / \mathrm{m}^{2}$. The samples were all evaluated in horizontal orientation and ignited using a spark igniter. Each experiment was repeated at least twice. Time to ignition (TTI), heat release rate (HRR), total heat release (THR), peak of heat release rate (pHRR), residue at flame out and effective heat of combustion (EHC) were recorded. The uncertainties on TTI, pHRR, THR and EHC are estimated to $5 \mathrm{~s}, 10 \%, 1 \mathrm{~kJ} /$ $\mathrm{g}$ and $1.5 \mathrm{~kJ} / \mathrm{g}$

\section{Results}

\subsection{Miscibility of PMMA and PLA}

The degradation during ageing of a polymer changes in presence of a second polymer [19]. Especially the degree of miscibility of a binary blend may modify the ageing of material. Therefore, miscibility of PMMA and PLA at different ratio was investigated using DSC. Fig. 1 shows the DSC curves for unfilled polymers and blends during the first and the second heating ramps. It can be observed that PLA exhibits cold crystallization at $100{ }^{\circ} \mathrm{C}$ and melting at $170{ }^{\circ} \mathrm{C}$ (Fig. 1a). These two phenomena are observed for the two heating ramps. From the difference between the enthalpies involved in both steps according to equation (4), the crystallinity degree of PLA at room temperature was $18 \%$. Cold crystallization and melting were also observed for PMMA/PLA 15/ 85 during the first heating ramp. However, the crystallinity degree of PLA was lower, $8 \%$ only. Cold crystallization disappears during the second ramp and the melting peak is much lower. This can be assigned to the inhibition of PLA crystallization by PMMA while both polymers are miscible. This inhibition increases when PMMA content increases. For PMMA/PLA 25/75, only a small melting peak is observed during the first ramp, but neither cold crystallization nor melting occur during the second ramp. The melting peak is almost negligible for PMMA/PLA 50/50 and corresponds to a crystallinity degree of no more than $6 \%$. Pure PMMA as well as PMMA/PLA 75/25 are fully amorphous, as no crystallization or melting steps occur.

During the first heating ramp, two glass transitions $\left(T_{g}\right)$ are observed for the blends (except for rich-PLA blends because the a
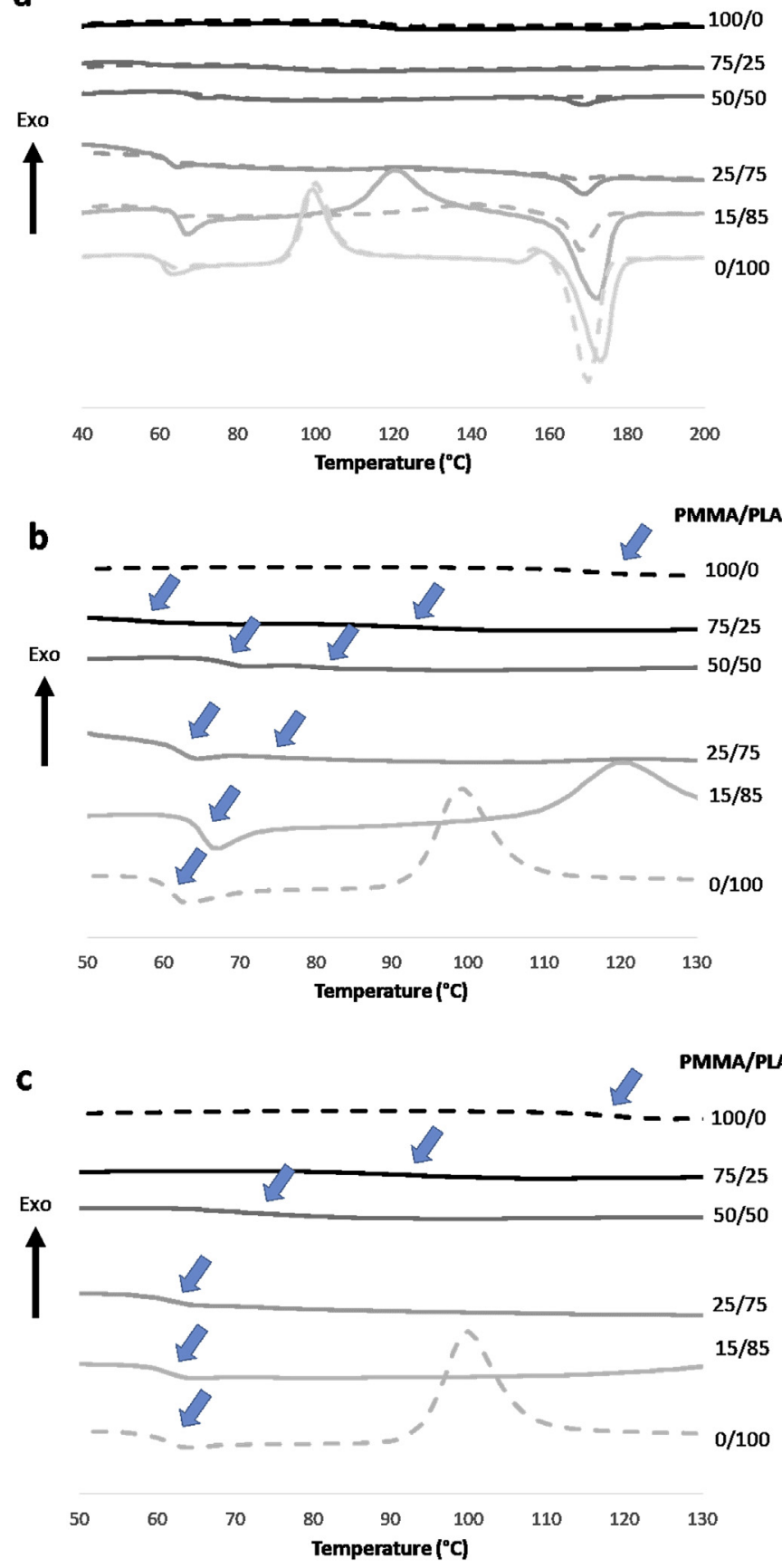

Fig. 1. DSC curves for various PMMA/PLA blends - a/First and second scans from 40 to $200{ }^{\circ} \mathrm{C}$ continuous lines correspond to the first heating ramp; dotted lines correspond to the second heating ramp, b/First scan, focus between 50 and $130{ }^{\circ} \mathrm{C}, \mathrm{c} /$ Second scan, focus between 50 and $130{ }^{\circ} \mathrm{C}$ - Blue arrows indicate glass transitions. (For interpretation of the references to colour in this figure legend, the reader is referred to the Web version of this article.)

glass transition of PMMA-rich phase is hardly visible - Fig. 1b). These temperatures do not correspond to the glass transition temperatures of pure PMMA and PLA ( 121 and $61^{\circ} \mathrm{C}$, respectively). It means that two phases are present but these phases are not pure and contain both PMMA and PLA in various fractions. Nevertheless, during the second heating ramp, only one glass transition is recorded, evidencing that both polymers are fully miscible (Fig. 1c). Fig. 2 shows the dependence of the glass transition temperature on the PMMA content. Well-known Fox and 


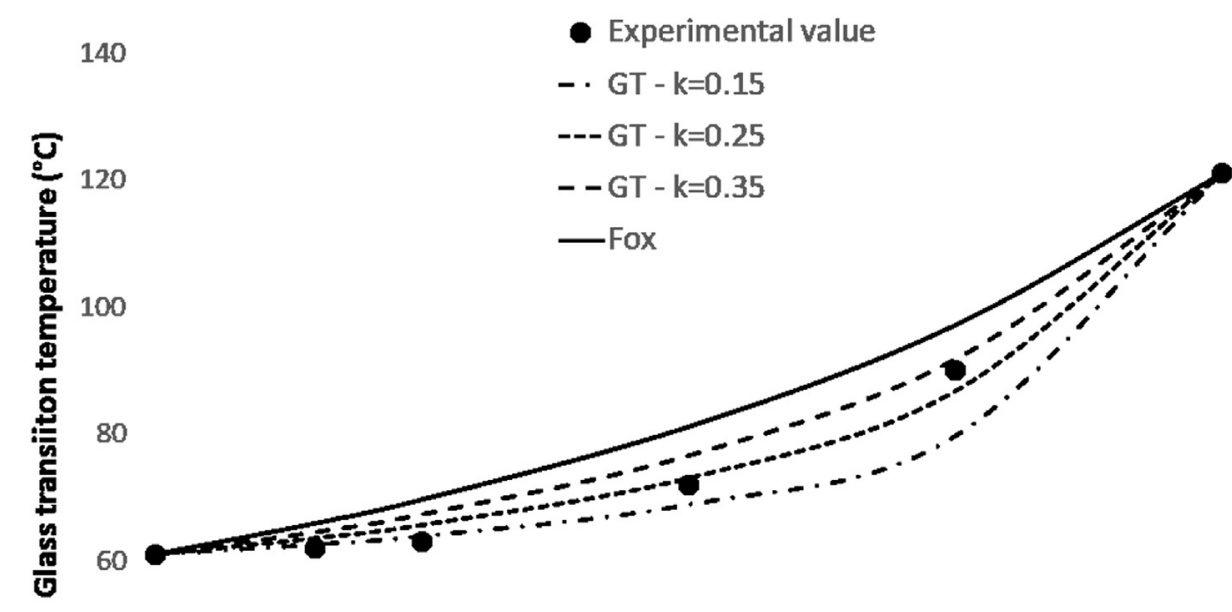

40

$\begin{array}{lllrrr}0 & 0.2 & 0.4 & 0.6 & 0.8 & 1 \\ & \text { PMMA fraction } & & \end{array}$

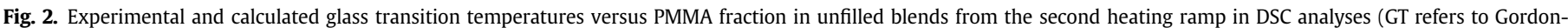
Taylor equation).

Gordon-Taylor models (respectively equations (5) and (6)) were used to calculate the glass transition temperature of the blends, based on the PMMA and PLA contents and their own glass transition temperatures. For Gordon-Taylor model, a fitting coefficient $\mathrm{K}$ is added. It can be noted that the $\mathrm{T}_{\mathrm{g}}$ of the studied blends changes continuously when PMMA fraction increases according to the Gordon-Taylor equation (with $\mathrm{K}$ close to 0.25 ). This result is in quite good agreement with the literature. Gonzalez-Gordon and al. noted that $\mathrm{K}$ value ranges between 0.2 and 0.4 depending on the grade of PLA and PMMA [20]. Anakabe et al. obtained the best fit with $K=0.24$ [21]. Zhang et al. found a slightly higher $K$ value (0.5) [22].

$\frac{1}{T g}=\frac{w_{P L A}}{T g_{P L A}}+\frac{w_{P M M A}}{T g_{P M M A}}$

(Fox)

$T g=\frac{w_{P L A} T g_{P L A}+K w_{P M M A} T g_{P M M A}}{w_{P L A}+K w_{P M M A}}$

(Gordon-Taylor)

All these analyses were carried out on extruded blends and pure polymers. After a first step at high temperature (namely extrusion), the blends are not fully miscible. After a further heating (namely the first heating ramp in DSC analysis), only one glass transition temperature is recorded during the second heating ramp. It can be concluded that PMMA and PLA are fully miscible in blends after the whole processing treatments, extrusion and injection-molding, involving two steps at high temperature. Moreover, all the materials are (almost) fully amorphous while crystallization of PLA in blends is almost fully inhibited, except pure PLA.

\subsection{Mass variation and phosphorus release during ageing}

During ageing, water diffuses into the bulk while PLA oligomers (generated from PLA hydrolysis) as well as phosphorus FR are released outside. Mass was measured after ageing before drying and after drying. Data are listed in Table 2. The mass change up to 3 weeks of ageing is also plotted in Fig. 3. The mass increases after 1 week of ageing due to water penetration for all formulations. A further increase is observed for longer ageing duration only for FR PMMA and FR PMMA/PLA 50/50. On the contrary, for the three other materials, the mass decreases because the loss of PLA and phosphorus becomes prominent over the water penetration.

The mass loss after drying increases with ageing and with PLA content. For FR PMMA, the loss is quite limited evidencing that the water is trapped into material and cannot be easily removed. Therefore, the final weight gain is positive, i.e. the mass increases due to water penetration and trapping.

The same conclusion can be assumed for FR PMMA/PLA 50/50, and the mass increase is even higher after 1 and 2 weeks of ageing. On the contrary, for PLA-rich materials, the drying leads to a significant mass loss and the final weight gain is significantly negative (up to $-33 \%$ after 3 weeks of ageing for FR PLA). Not only the water was removed, but also a fraction of APP and PLA was extracted in water.

Consequently, the phosphorus content (measured independently by ICP/AES) drops during ageing. After 3 weeks, the phosphorus is almost totally removed from FR PLA. On the contrary, no significant decrease is observed for FR PMMA. A decrease is noted for blends. Higher is the initial PLA content, lower is the phosphorus content after ageing.

In Fig. 3, it is noteworthy that the mass loss after drying is almost linear versus the PLA content. On the contrary, the mass change after ageing (and before drying) does not follow a linear rule of mixtures. Especially, a significant gain is observed for FR PMMA/ PLA 50/50 despite the fact that PLA is not protected by the presence of PMMA versus hot hydrolysis as shown below. This unexpected gain shows that the competition between several phenomena (water diffusion, removal of phosphorus and PLA oligomers) depends on composition in a complex way.

The decrease of phosphorus content versus ageing time can be modelled using a simple phenomenological equation as follows (equation (7)): 
Table 2

Mass variation and phosphorus content (measured by ICP-AES) during ageing for each formulation (standard deviation $\pm 0.1-0.6 \%$ ).

\begin{tabular}{|c|c|c|c|c|}
\hline Sample code & $\begin{array}{l}\text { Mass variation after ageing before drying } \\
W_{a}(\mathrm{wt} \%)\end{array}$ & $\begin{array}{l}\text { Mass variation during drying } \\
-W_{u p}(\mathrm{wt} \%)\end{array}$ & $\begin{array}{l}\text { Final weight gain } \\
\mathrm{W}_{f}(\mathrm{wt} \%)\end{array}$ & Phosphorus content (wt\%) \\
\hline \multicolumn{5}{|l|}{ Before ageing } \\
\hline PMMA/APP/S9 & 1 & I & 1 & 3.51 \\
\hline PMMA/PLA/APP/S9 50/50 & 1 & i & i & 3.3 \\
\hline PMMA/PLA/APP/S9 25/75 & i & l & 1 & 3.47 \\
\hline PMMA/PLA/APP/S9 15/85 & 1 & l & 1 & 3.47 \\
\hline $\mathrm{PLA} / \mathrm{APP} / \mathrm{S9}$ & 1 & i & 1 & 3.25 \\
\hline \multicolumn{5}{|l|}{ After 1 week of ageing } \\
\hline PMMA/APP/S9 & 6.2 & -1.2 & 4.9 & 1 \\
\hline PMMA/PLA/APP/S9 50/50 & 18.2 & -9.3 & 8.9 & 3.21 \\
\hline PMMA/PLA/APP/S9 25/75 & 5.2 & -8.6 & -3.8 & 1.95 \\
\hline PMMA/PLA/APP/S9 15/85 & 3.6 & -9.7 & -6.4 & 1.69 \\
\hline PLA/APP/S9 & -2 & -11.1 & -12.9 & 1.23 \\
\hline \multicolumn{5}{|l|}{ After 2 weeks of ageing } \\
\hline PMMA/APP/S9 & 8.8 & -1.2 & 7.4 & 1 \\
\hline PMMA/PLA/APP/S9 50/50 & 22.3 & -9.9 & 11.3 & 2.6 \\
\hline PMMA/PLA/APP/S9 25/75 & 2.3 & -14.8 & -13 & 1.15 \\
\hline PMMA/PLA/APP/S9 15/85 & 0.9 & -17.4 & -16.8 & 0.88 \\
\hline PLA/APP/S9 & -5.6 & -20.9 & -25.7 & 0.67 \\
\hline \multicolumn{5}{|l|}{ After 3 weeks of ageing } \\
\hline PMMA/APP/S9 & 10.2 & -1.2 & 8.9 & 3.34 \\
\hline PMMA/PLA/APP/S9 50/50 & 21.2 & -11.1 & 8.3 & 2.11 \\
\hline PMMA/PLA/APP/S9 25/75 & -0.3 & -19.7 & -20.1 & 0.85 \\
\hline PMMA/PLA/APP/S9 15/85 & -2.4 & -21.5 & -23.5 & 0.67 \\
\hline PLA/APP/S9 & -7.9 & -28.6 & -33.6 & 0.29 \\
\hline
\end{tabular}

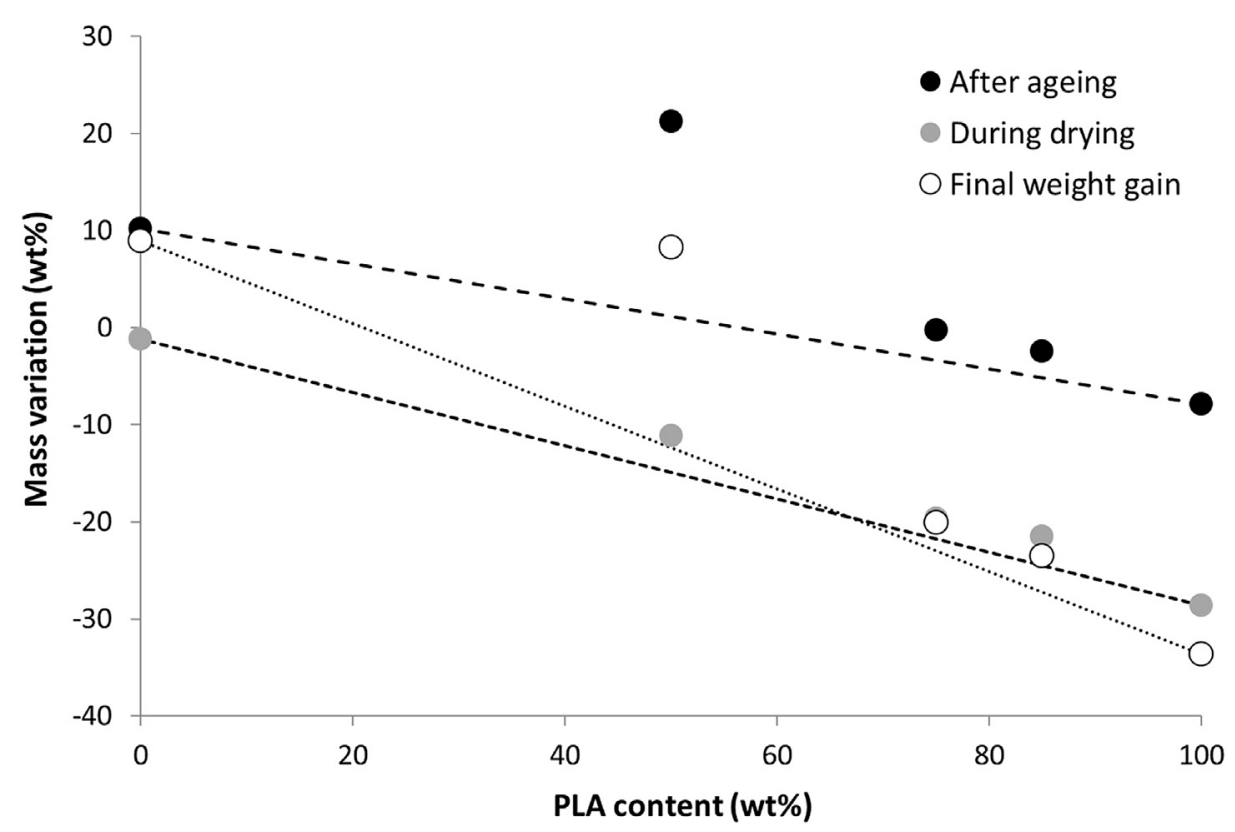

Fig. 3. Mass variation after 3 weeks ageing before drying, during drying and final weight gain for the different flame retarded formulations.

$P_{P M M A-P L A}(100-X) / X(t)=P_{0} \times e^{-k_{X} t}$

With $P_{0}$ the phosphorus content before ageing, the ageing time (in weeks) and $k_{x}$ a constant for the blend containing X wt\% of PLA.

Fig. 4 shows the experimental phosphorus contents as well as the corresponding modelled curves versus ageing time for each flame retarded formulation. Table 3 lists the values of $k$ depending on PLA content. It can be observed that $\mathrm{k}$ increases when PLA content increases, i.e. the phosphorus content decreases faster with ageing time. Fig. 5 show the $\mathrm{k}$ values versus PLA content. The $\mathrm{k}$ values for PLA and blends seem to be proportional to PLA content. By extrapolating this tendency to $\mathrm{k}=0$, it is expected that the phosphorus loss during ageing becomes null for a PLA content close to $40 \mathrm{wt} \%$. However, even for flame retarded PMMA, the experimental phosphorus loss is not null and a power law fits the data as well (with a very low $k$ value).

\subsection{Molecular weight analysis}

As aliphatic polyesters, PLA is very sensitive to hydrolysis, especially at temperatures higher than its glass transition temperature. Indeed, the high mobility of PLA chains promotes hydrolysis [23]. Molecular weights of PLA and PMMA were measured before and after ageing of FR PLA, FR PMMA and FR PMMA/PLA 50/50 (Table 4). Before ageing, both polymers have close values of $M_{n}$ and 


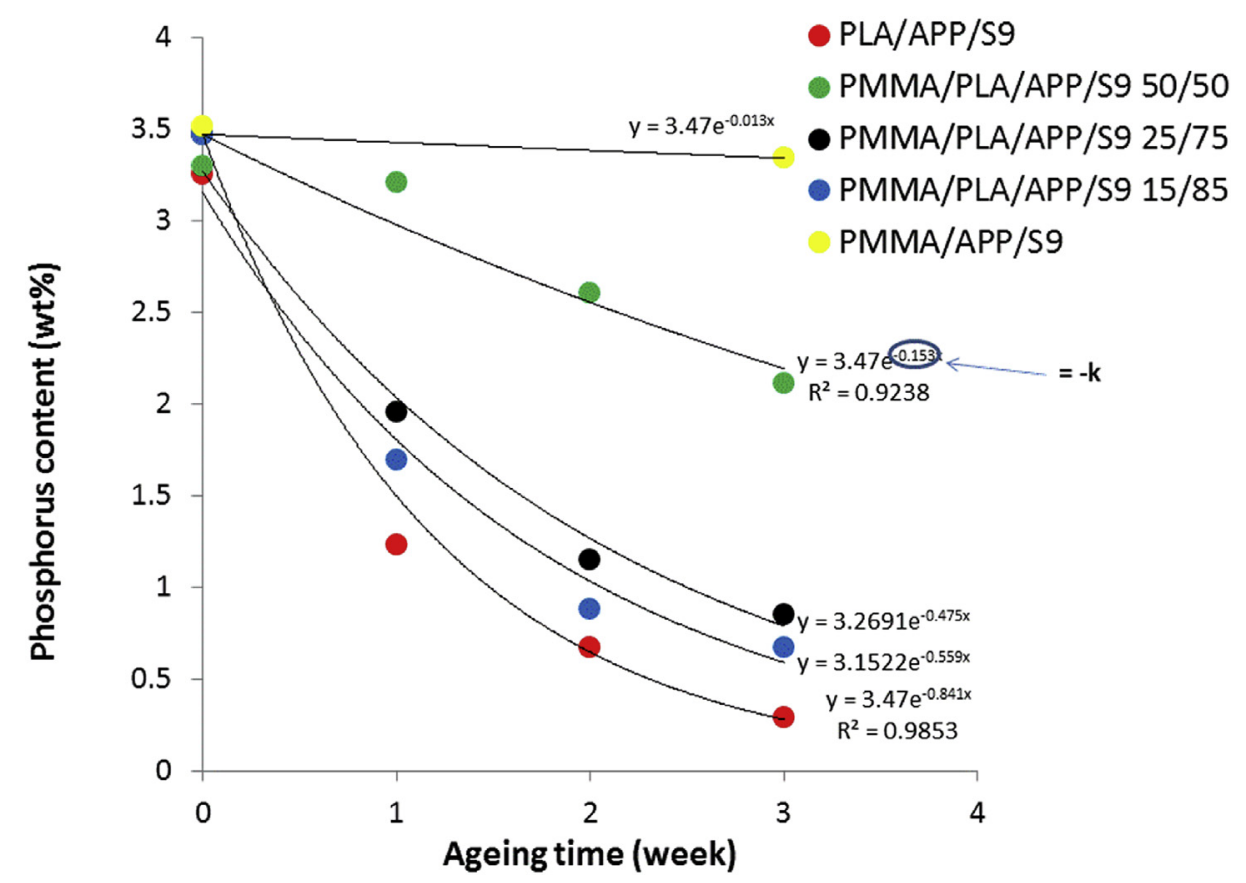

Fig. 4. Phosphorus content versus ageing time.

Table 3

value of kx versus PLA content.

\begin{tabular}{ll}
\hline PLA content $(\mathrm{X})(\mathrm{wt} \%)$ & $\mathbf{k}_{\boldsymbol{X}}$ \\
\hline 0 & 0.013 \\
50 & 0.153 \\
75 & 0.475 \\
85 & 0.559 \\
100 & 0.841 \\
\hline
\end{tabular}

$M_{w}$. After 3 weeks of ageing, molecular weight of PMMA in FR PMMA does not change significantly. On the contrary, a drastic decrease of PLA molecular weight in FR PLA is observed: from $48354 \mathrm{~g} / \mathrm{mol}$ to $2184 \mathrm{~g} / \mathrm{mol}$ and from $71870 \mathrm{~g} / \mathrm{mol}$ to $2979 \mathrm{~g} / \mathrm{mol}$ respectively for $M_{n}$ and $M_{w}$.

While both polymers have initially similar molecular weight, only one peak is detected for FR PMMA/PLA. After ageing, two peaks are identified corresponding to the two peaks observed for FR PMMA and FR PLA. In other words, PLA was strongly hydrolyzed $\left(\mathrm{M}_{\mathrm{n}}\right.$ ad $\mathrm{M}_{\mathrm{w}}$ decrease respectively to $2603 \mathrm{~g} / \mathrm{mol}$ and $\left.3950 \mathrm{~g} / \mathrm{mol}\right)$ while PMMA was not affected by ageing. It can be assumed that PMMA does not protect PLA from hot hydrolysis even in the PMMA/

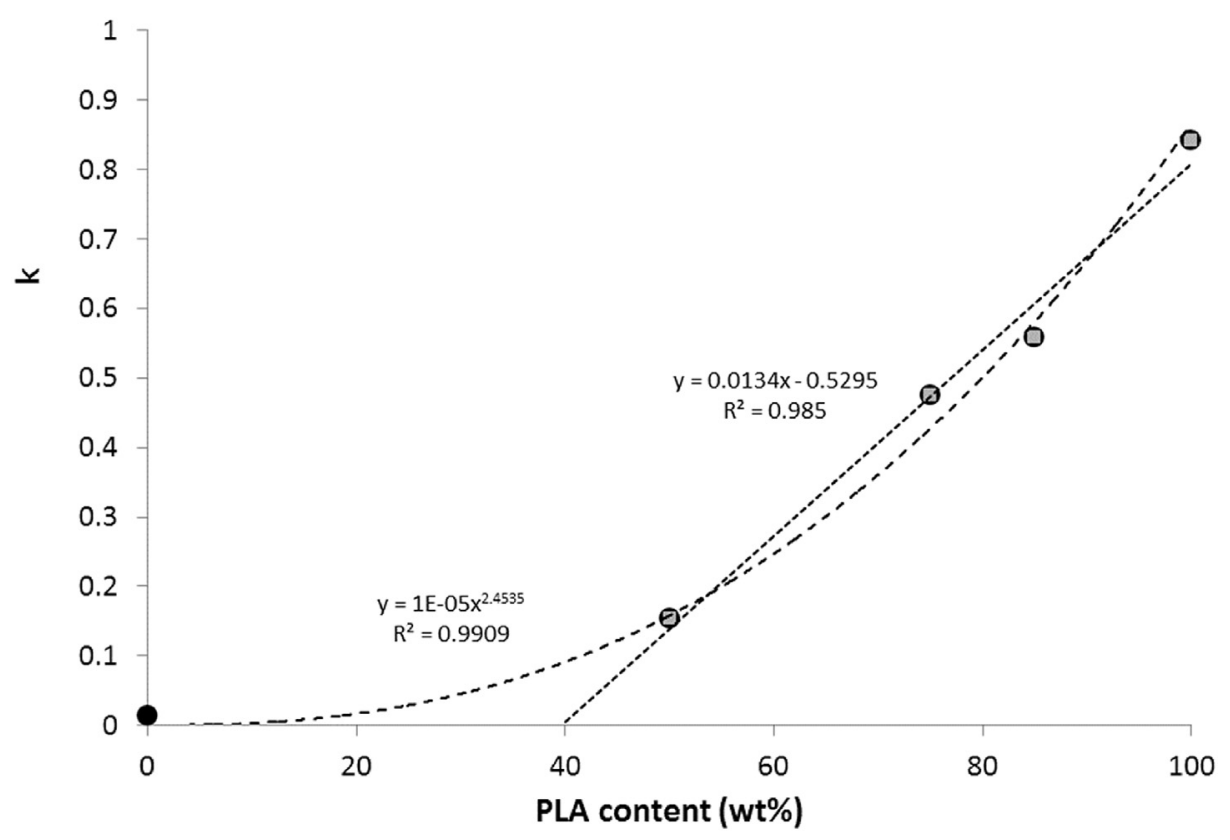

Fig. 5. $\mathrm{k}$ values versus PLA content in flame retarded blends. 
Table 4

Molecular weight versus ageing time for flame retarded materials.

\begin{tabular}{|c|c|c|c|c|c|c|}
\hline \multirow{2}{*}{ PLA content (wt\%) } & \multicolumn{3}{|c|}{ Before ageing } & \multicolumn{3}{|c|}{ After 3 weeks ageing } \\
\hline & $\mathrm{Mn}(\mathrm{g} / \mathrm{mol})$ & $\mathrm{Mw}(\mathrm{g} / \mathrm{mol})$ & Polydispersity index & $\operatorname{Mn}(\mathrm{g} / \mathrm{mol})$ & $\mathrm{Mw}(\mathrm{g} / \mathrm{mol})$ & Polydispersity index \\
\hline 0 & 50370 & 84736 & 1.67 & 52168 & 86922 & 1.67 \\
\hline \multirow[t]{2}{*}{50} & 38605 & 70430 & 1 & 47895 & 84376 & I \\
\hline & & & & 2603 & 3950 & \\
\hline 100 & 48354 & 71870 & 1.49 & 2184 & 2979 & 1.36 \\
\hline
\end{tabular}
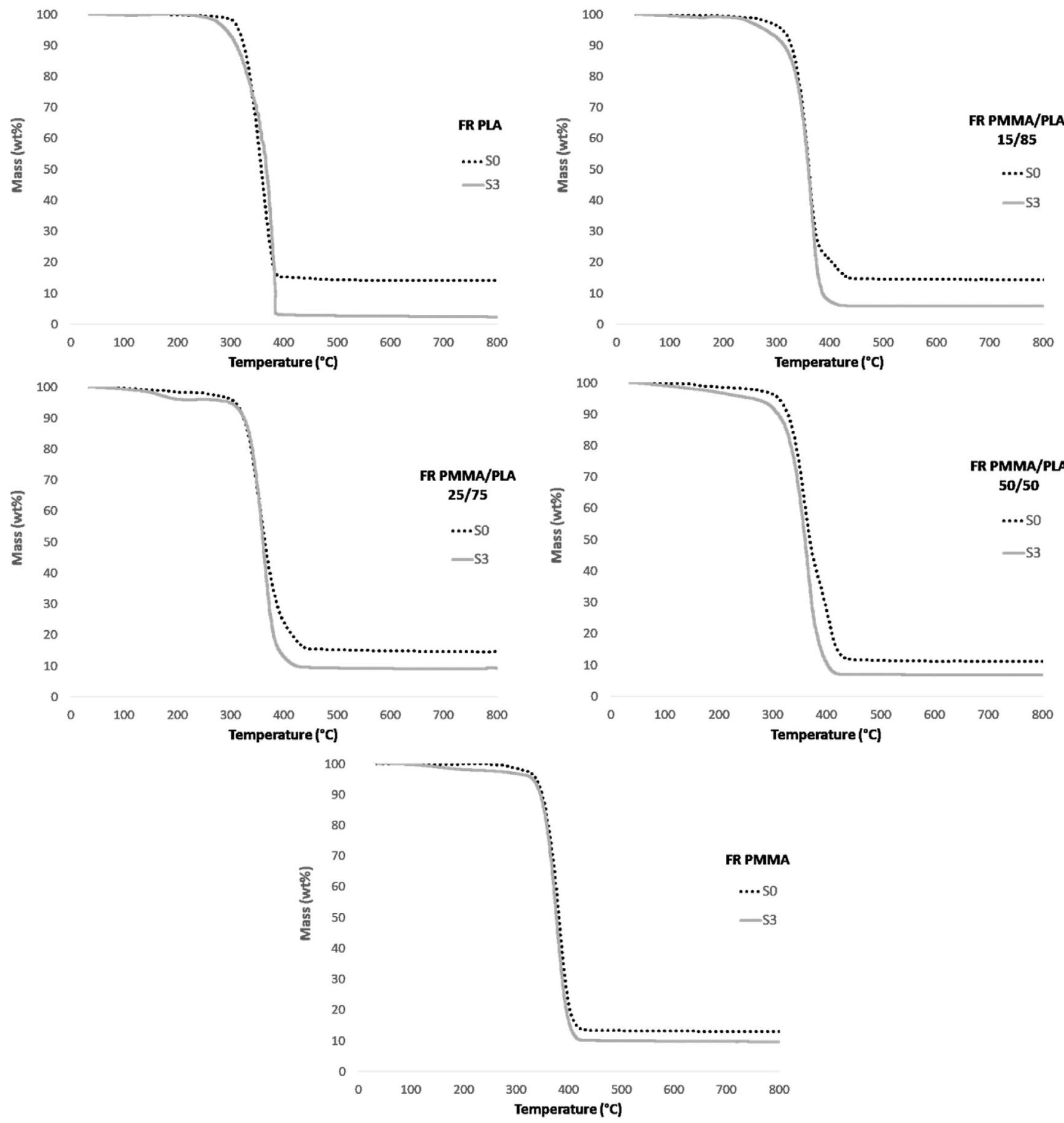

Fig. 6. TGA curves for the flame retarded formulations before and after 3 weeks of ageing. 
PLA 50/50 blend (i.e. the most resistant to ageing blend according to fire test - see below).

\subsection{Thermal degradation before and after ageing}

TG analyses were performed for all the formulations before and after 3 weeks of ageing (Fig. 6). One main apparent degradation step is observed due to the decomposition of both polymers in the same range of temperatures. The temperature of decomposition does not change after ageing even if the main step splits in two stages for FR blends. It can be explained by the sensitivity of PLA to hydrolysis, and consequently an earlier degradation. A first small mass loss step is recorded after ageing at low temperature (around $200{ }^{\circ} \mathrm{C}$ ) in the case of PMMA-rich formulations, probably due to residual water trapped into materials despite drying.

The main change occurring during ageing is the decrease in residue content. Residue is due partially to sepiolite and partially to charring of polymers in presence of APP. As evidenced previously, a significant fraction of phosphorus is removed during ageing, especially for PLA-rich formulations. A decrease in phosphorus content prevents the charring of polymers. In addition, a removal of sepiolite into water by erosion may not be excluded. Fig. 7 shows the difference in residue content before and after ageing versus PLA content. This difference is higher when PLA content is higher (12 wt\% for FR PLA versus less than $4 \mathrm{wt} \%$ for FR PMMA).

\subsection{Fire behaviour before and after ageing}

Fig. 8 shows the HRR curves for all flame retarded materials tested using the cone calorimeter. Main data are listed in Table 5. It can be found that the pHRR of all formulations before ageing is close to $300 \mathrm{~kW} / \mathrm{m}^{2}$ (400 $\mathrm{kW} / \mathrm{m}^{2}$ for FR PMMA). For FR PLA and PMMA/PLA 25/75 and 15/85, a second PHRR is observed at the end of the test and can be assigned to a breakdown of the residue layer and release of gases into flame. After 1 week ageing, the pHRR does not greatly change but the curve shape is modified for
PLA-rich formulations. Especially, the decrease after pHRR is more limited and a plateau at higher HRR is observed. The second pHRR is vanished. After 2 weeks, the pHRR is strongly enhanced to $450-500 \mathrm{~kW} / \mathrm{m}^{2}$ for these formulations. The decrease after pHRR is faster up to flame out. Between 2 and 3 weeks, there is no significant change. On the contrary for FR PMMA and PMMA/PLA 50/50 blend, the PHRR does not increase and HRR curve is only slightly modified, even after 3 weeks of ageing (Fig. 9).

It can be also found that THR increases for PLA-rich formulations after ageing, from 14.4 to $16.6 \mathrm{~kJ} / \mathrm{g}$ for FR PLA and from 16.6 to $18.9 \mathrm{~kJ} / \mathrm{g}$ for FR PMMA/PLA 25/75. This can be ascribed to the decrease of residue content, corresponding to a higher amount of fuels released in gas phase. Residue content decreases from 11.7 to $3.5 \mathrm{wt} \%$ for FR PLA and from 12.4 to $5.4 \mathrm{wt} \%$ for FR PMMA/PLA 25/ 75. The decrease of residue content is also observed for FR PMMA and FR PMMA/PLA 50/50 but at a much lower extent. Even after 3 weeks of ageing, the residue content remains higher than $10 \mathrm{wt} \%$. Fig. 7 shows the difference between residue contents before and after ageing. The tendency is the same as for TGA: higher is the PLA content, higher is the decrease in residue content.

The effective heat of combustion (EHC) slightly increases for the PLA-rich formulations, due to the lower char content (char stores usually a huge amount of heat). On the contrary, EHC decreases slightly for FR PMMA and FR PMMA/PLA 50/50. The decrease is maximum for the latter (from 20.4 to $18.2 \mathrm{~kJ} / \mathrm{g}$ ). This may be assigned to water trapped into this formulation after ageing, as revealed previously (see Table 2 ). The water is released during fire tests and reduces the EHC value.

Time-to-ignition (TTI) is significantly higher for FR PLA. TTI is more or less constant for all formulations after ageing whichever the ageing duration, except for FR PMMA/PLA 50/50. Indeed, TTI increased from 28 to $50 \mathrm{~s}$ after 3 weeks of ageing. Once again, this may be assigned to water contained into this material. Water release dilutes fuels and delays the ignition requiring a minimal concentration of fuels in gas phase.

Phosphorus FRs are well known as efficient char promoters. Therefore, the decrease in phosphorus content due to ageing

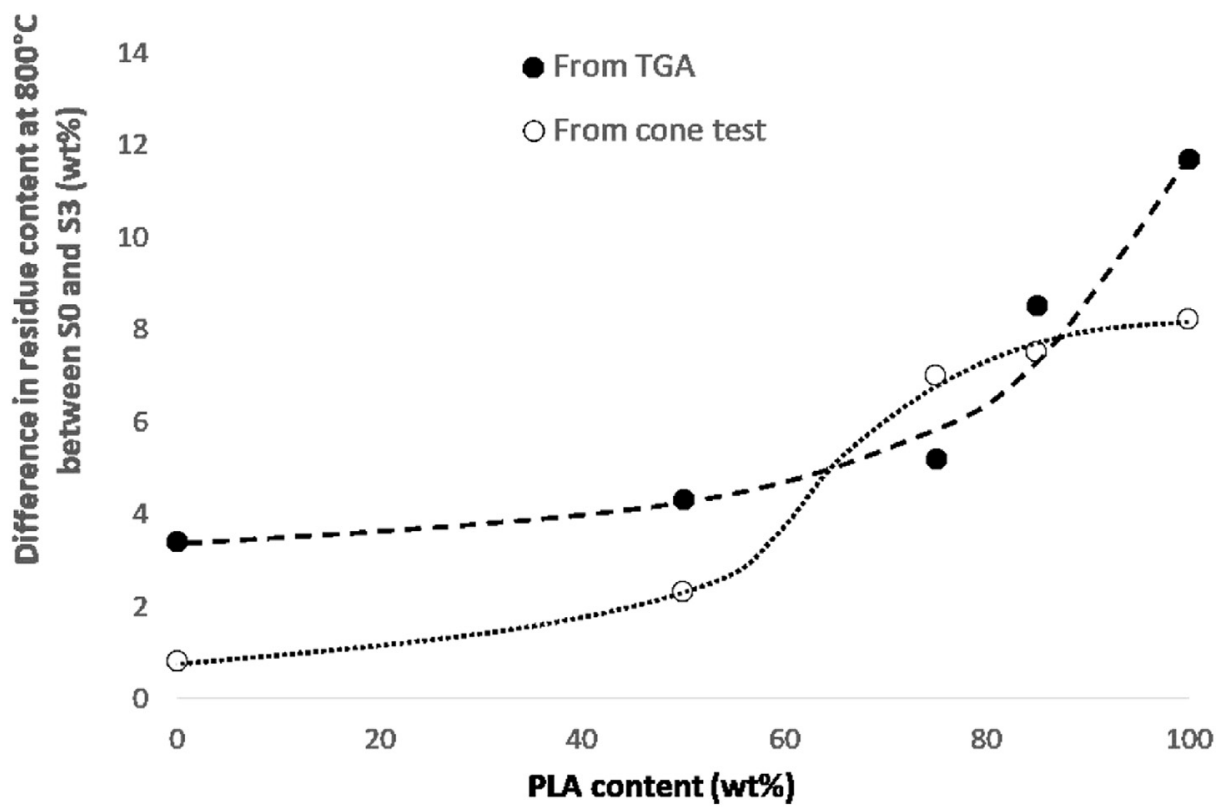

Fig. 7. Difference between residue contents before and after 3 weeks of ageing versus PLA content (from TGA and cone tests). 

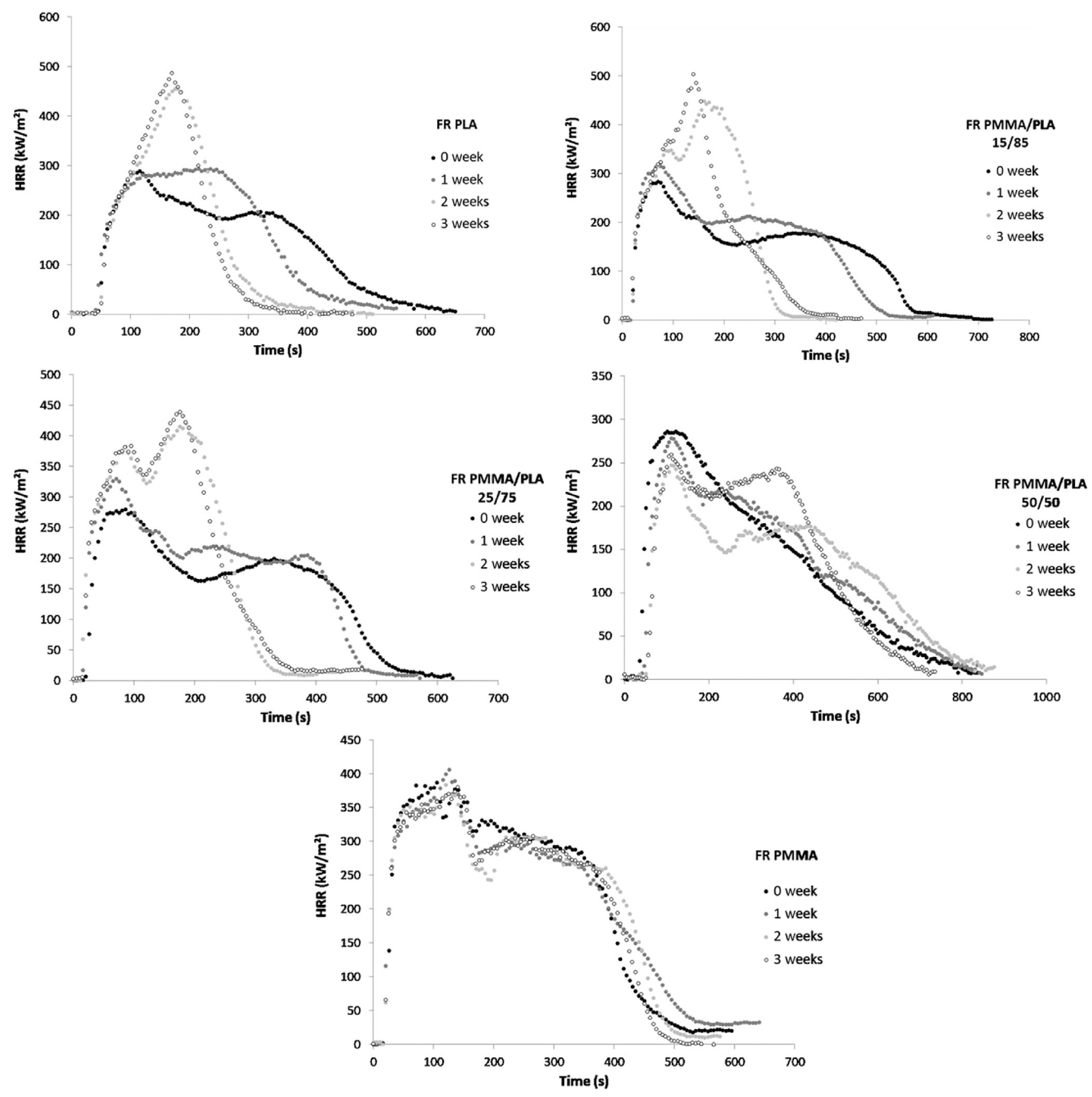

Fig. 8. HRR curves of each flame retarded formulation for various ageing times.

should lead to a decrease in charring. Fig. 10 shows the rough relation between the residue content and the phosphorus content for all formulations (keep in mind that all formulations initially exhibit similar residue contents). When phosphorus content drops from $3.5 \mathrm{wt} \%$ to less than $0.5 \mathrm{wt} \%$, the residue content decreases from 12 to $13 \mathrm{wt} \%$ to $4-5 \mathrm{wt} \%$.

Fig. 11 shows the reduced pHRR (i.e. the pHRR after ageing divided by the initial pHRR of the same material) versus the phosphorus content. The reduced pHRR is equal to 1 before ageing for each formulation. It can be highlighted that the reduced pHRR does not change as long as the phosphorus content is high enough ( $2 \mathrm{wt} \%$ or more). A limited increase is observed when phosphorus content is in the range $1-2 \mathrm{wt} \%$ : reduced pHRR increases up to 1.2
(20\% increase). When phosphorus content becomes lower than $1 \mathrm{wt} \%$ after a given ageing time (for flame retarded PLA and blends PMMA/PLA 15/85 and 25/75), the reduced pHRR significantly increases. Its value is in the range $1.5-1.8$ (50-80\% increase).

\section{Discussion}

The incorporation of PMMA significantly decreases the rate of FR release during ageing. However, at the same time the biobased fraction of the formulation was decreased. According to Fig. 5, the PMMA content needed to fully prevent the phosphorus release should be at least $60 \mathrm{wt} \%$. Moreover, it does not prove that PMMA has a protective effect. Indeed, to evidence such protective effect, 
Table 5

Flammability data from cone calorimeter tests.

\begin{tabular}{|c|c|c|c|c|c|}
\hline Sample code & TTI (s) & $\mathrm{pHRR}\left(\mathrm{kW} / \mathrm{m}^{2}\right)$ & THR $(\mathrm{kJ} / \mathrm{g})$ & Residue content (wt\%) & Effective heat of combustion $(\mathrm{kJ} / \mathrm{g})$ \\
\hline \multicolumn{6}{|l|}{ Before ageing } \\
\hline PMMA/APP/S9 & 22 & 402 & 20.4 & 11.5 & 23.1 \\
\hline PMMA/PLA/APP/S9 50/50 & 28 & 289 & 17.8 & 12.9 & 20.4 \\
\hline PMMA/PLA/APP/S9 25/75 & 22 & 284 & 16.6 & 12.4 & 18.8 \\
\hline PMMA/PLA/APP/S9 15/85 & 17 & 289 & 15.4 & 12.4 & 17.3 \\
\hline PLA/APP/S9 & 40 & 291 & 14.4 & 11.7 & 16.4 \\
\hline \multicolumn{6}{|l|}{ After 1 week of ageing } \\
\hline PMMA/APP/S9 & 18 & 407 & 20.7 & 11.8 & 23.5 \\
\hline PMMA/PLA/APP/S9 50/50 & 40 & 281 & 16.8 & 12.3 & 18.6 \\
\hline PMMA/PLA/APP/S9 25/75 & 15 & 332 & 16.8 & 7.7 & 18.5 \\
\hline PMMA/PLA/APP/S9 15/85 & 18 & 322 & 16.1 & 6.8 & 17.6 \\
\hline PLA/APP/S9 & 36 & 297 & 16.2 & 5.6 & 17.4 \\
\hline \multicolumn{6}{|l|}{ After 2 weeks of ageing } \\
\hline PMMA/APP/S9 & 20 & 389 & 20.2 & 10.7 & 22.8 \\
\hline PMMA/PLA/APP/S9 50/50 & 48 & 250 & 16.0 & 11.9 & 18.3 \\
\hline PMMA/PLA/APP/S9 25/75 & 13 & 427 & 17.6 & 6.7 & 18.9 \\
\hline PMMA/PLA/APP/S9 15/85 & 17 & 454 & 16.6 & 6.9 & 17.8 \\
\hline PLA/APP/S9 & 44 & 460 & 16.2 & 4.3 & 17.2 \\
\hline \multicolumn{6}{|l|}{ After 3 weeks of ageing } \\
\hline PMMA/APP/S9 & 18 & 373 & 19.6 & 10.7 & 22.2 \\
\hline PMMA/PLA/APP/S9 50/50 & 50 & 266 & 16.3 & 10.6 & 18.2 \\
\hline PMMA/PLA/APP/S9 25/75 & 14 & 439 & 18.9 & 5.4 & 20.1 \\
\hline PMMA/PLA/APP/S9 15/85 & 17 & 503 & 17.1 & 4.9 & 18.2 \\
\hline PLA/APP/S9 & 41 & 487 & 16.6 & 3.5 & 17.2 \\
\hline
\end{tabular}

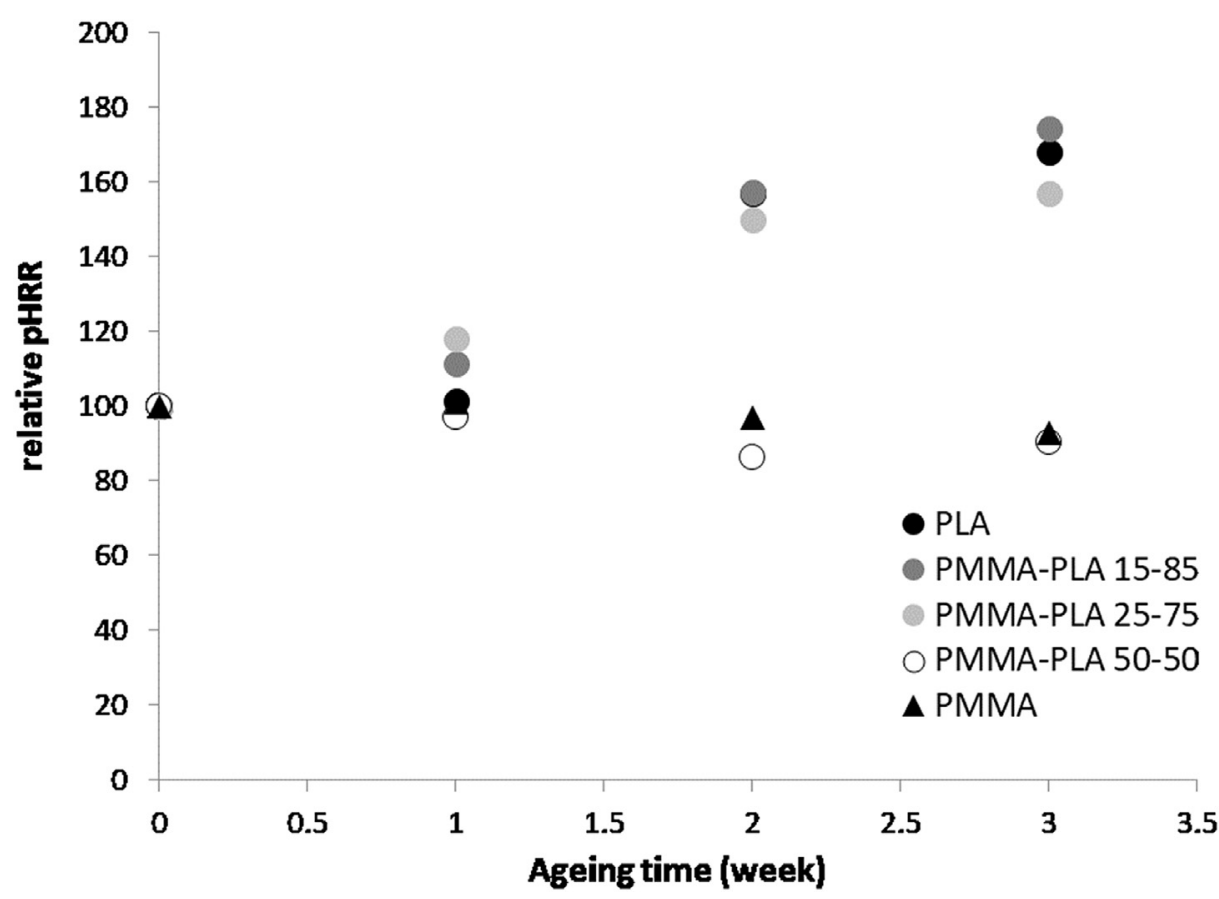

Fig. 9. Relative pHRR versus ageing time for each flame retarded formulation.

the release of FR in PMMA/PLA blend (equation (7)) should be slower than that calculated according to a rule of mixtures (equation (8)).

$P_{P M M A-P L A(100-X) / X}(t)=P_{0} \times\left(X \times e^{-k_{100} t}+(100-X) \times e^{-k_{0} t}\right)$

Figs. 12-14 compare the decrease in phosphorus content according to equations ( 7 ) and ( 8 ) for the three flame retarded blends PMMA-PLA 50/50, 25/75 and 15/85. It is highlighted that the decrease of phosphorus content in blend 50/50 is effectively slower than expected according to a linear rule of mixtures. Nevertheless, it is no longer the case for blends $25 / 75$ and $15 / 85$. The incorporation of PMMA in these blends limits the release of FR proportionally to its weight fraction but probably cannot be considered as a suitable protective strategy.

This may be ascribed to the glass transition temperature. Indeed, all these blends are miscible and exhibit only one $T_{g}$, which depends on the composition. Ageing temperature is fixed at $70{ }^{\circ} \mathrm{C}$ This temperature is higher than the $T_{g}$ of PLA but also of blends PMMA-PLA $15 / 85$ and $25 / 75$. In that case, the water diffusion should be very fast. Indeed, several authors have already evidenced that the water diffusion in PLA increases significantly when the 


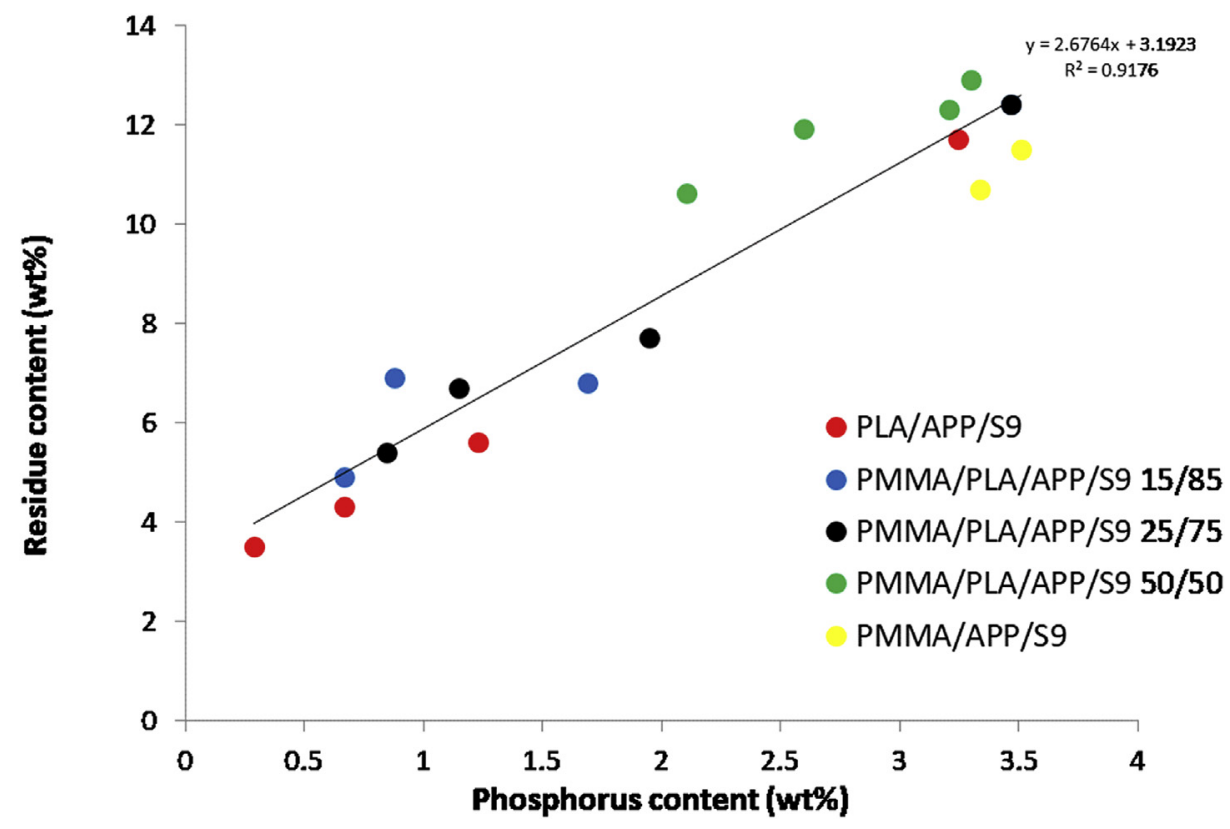

Fig. 10. Residue content (wt\%) versus phosphorus content (wt\%) for each flame retarded formulation.

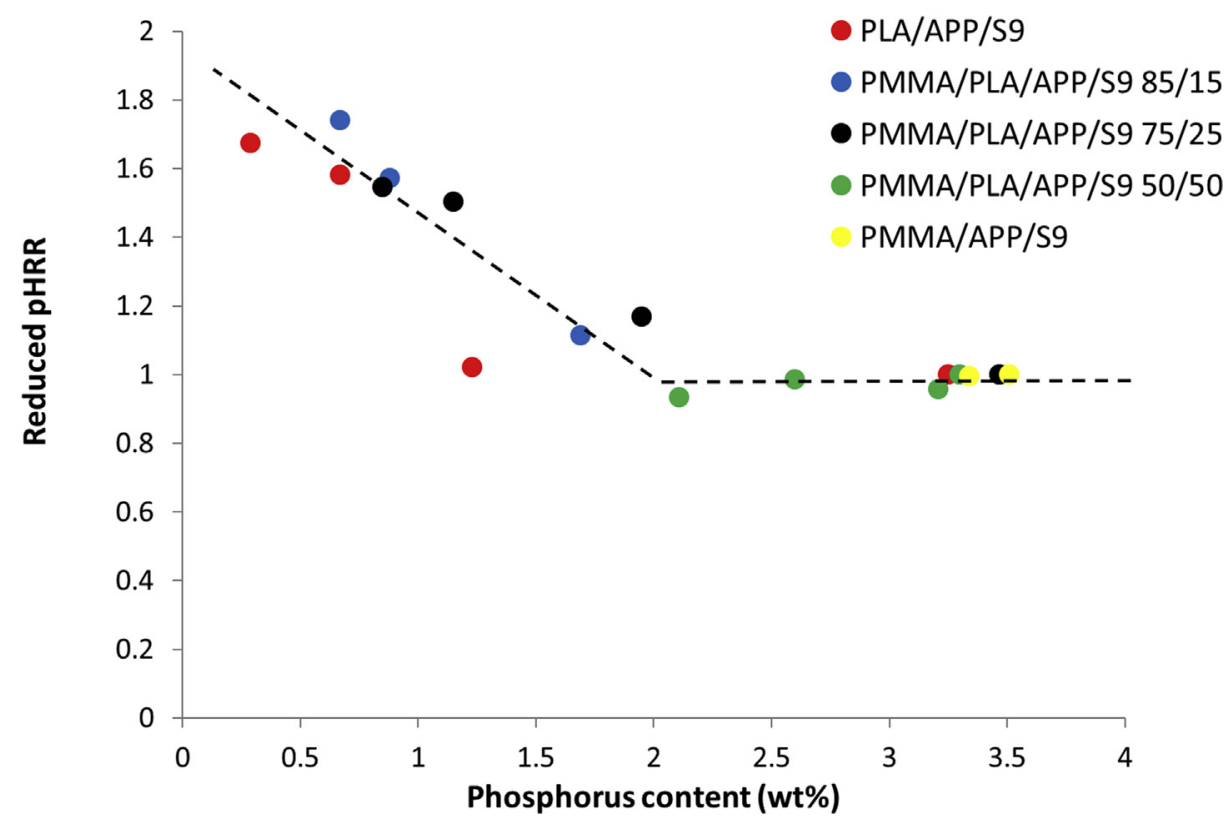

Fig. 11. Reduced pHRR versus phosphorus content for each flame retarded formulation (dotted line is only done for eye guideline).

ageing temperature is approaching the glass transition temperature $[23,24]$. Only pure PMMA and PMMA-PLA 50/50 exhibit a $T_{g}$ higher than $70{ }^{\circ} \mathrm{C}$, limiting drastically the water diffusion and FR release. Note that the PLA fraction in blends may slightly reduce during ageing due to oligomers extraction but according to Gordon-Taylor equation, this reduction should not be significant enough to lead to a $\mathrm{T}_{\mathrm{g}}$ higher than $70^{\circ} \mathrm{C}$. Moreover, Jimenez et al. [12,13] showed that the reduction in PLA molecular weight promoted by hydrolysis is correlated to a decrease in glass transition temperature that enhances the release of APP.

Therefore, in order to improve the resistance to ageing in hot water, the incorporation of a second polymer in a miscible polymer blend should be chosen to increase the $T_{g}$ above the ageing temperature. Nevertheless, it is noteworthy that even in this case the protective effect is quite limited (see Fig. 12 for blend 50/50).

\section{Conclusion}

In the case of water immersion ageing, fire behavior may be preserved by incorporation of PMMA into flame retarded PLA. Water penetration was reduced as well as the removal of phosphorus into ageing medium. While the phosphorus content into the material remains higher than a critical value (around 1-2 wt\%), the protective residue is maintained and the heat release rate curve in cone calorimeter is unaffected. 


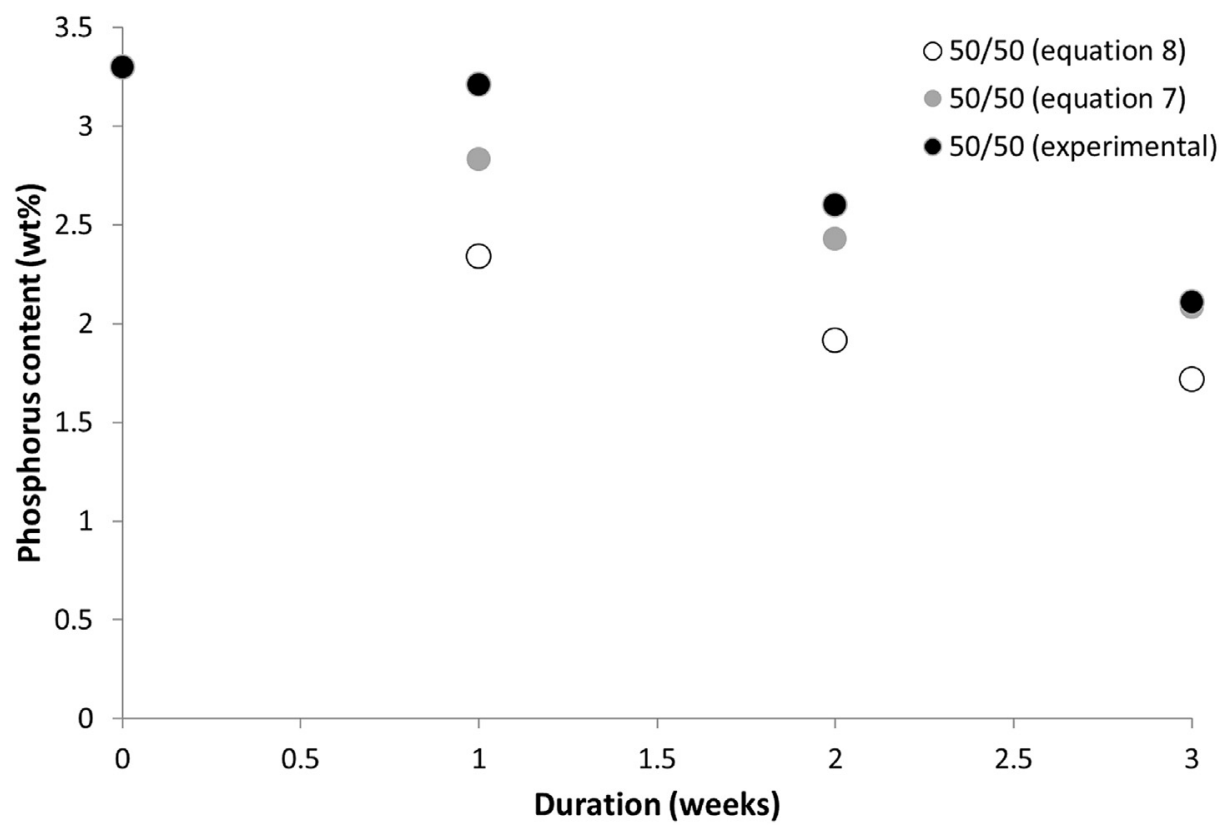

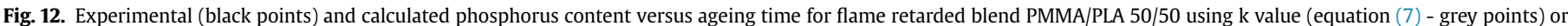
using a linear rule of mixtures (equation (8) - white points).

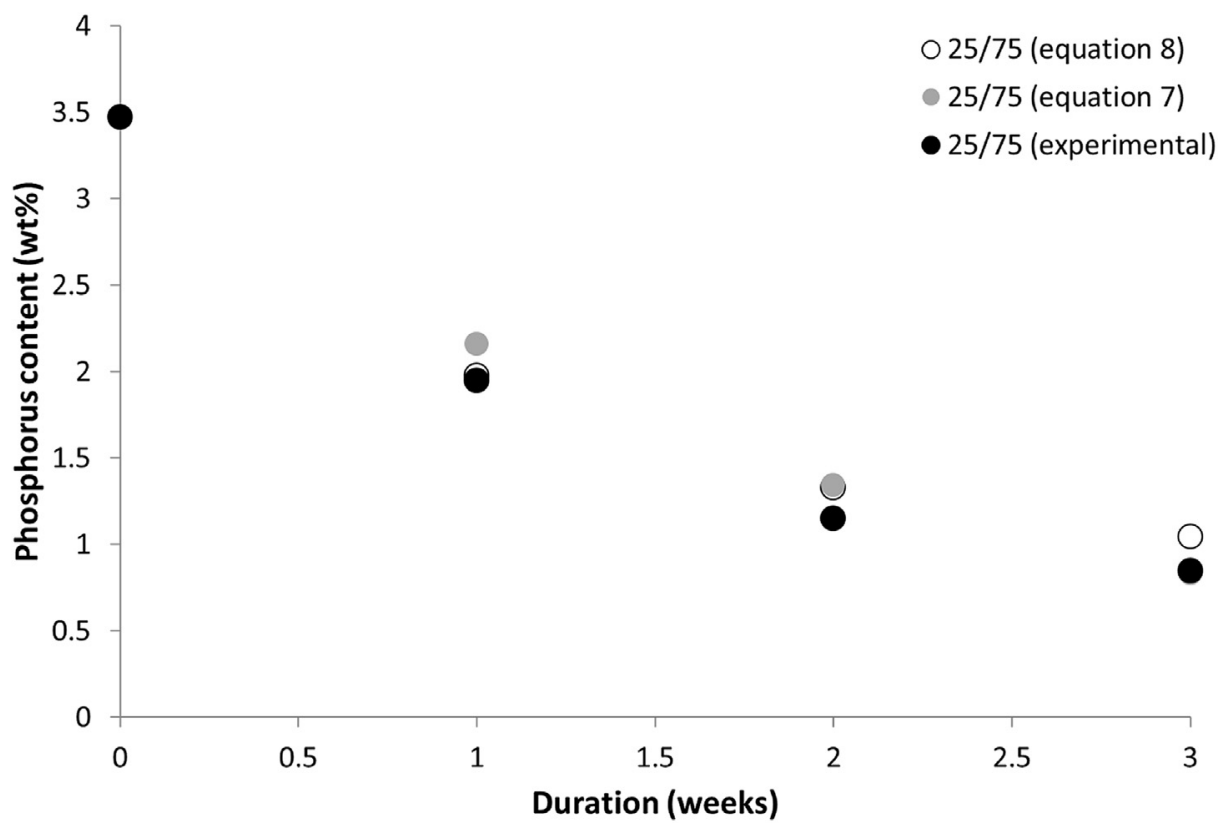

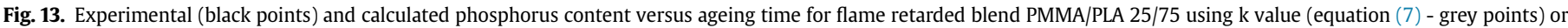
using a linear rule of mixtures (equation (8) - white points).

Nevertheless, the protective effect of PMMA is questionable. PMMA does not protect PLA from hydrolysis. Moreover, for low amount of PMMA, the slowdown of phosphorus release is no more than calculated according to a linear rule of mixtures. In other words, the release of phosphorus is proportional to PLA content. A real protective effect is observed only for higher PMMA content (close to $50 \mathrm{wt} \%$ ). In that case, the release of phosphorus is slower than calculated.

These observations can be assigned to the changes of the glass transition temperature which follows the Gordon-Taylor equation for the blends PMMA/PLA. This temperature is lower than the ageing temperature $\left(70^{\circ} \mathrm{C}\right)$ for PLA-rich materials. When PMMA content increases to $50 \mathrm{wt} \%$, this temperature becomes higher than the ageing temperature and consequently the removal of phosphorus is slowed down. However even in this case, the protective effect of PMMA remains quite limited.

\section{Declaration of competing interest}

The authors declare that they have no known competing 


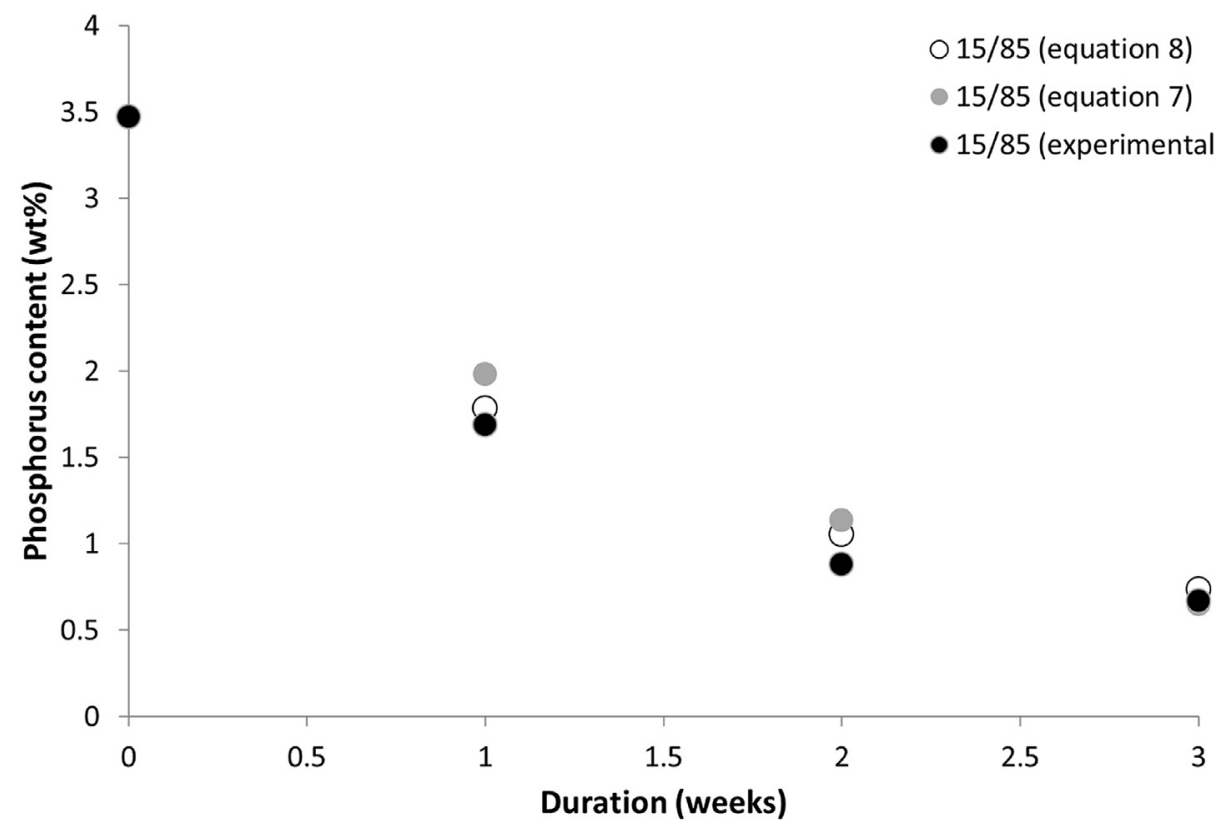

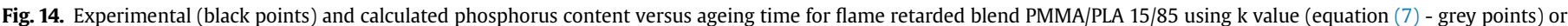
using a linear rule of mixtures (equation (8) - white points).

financial interests or personal relationships that could have appeared to influence the work reported in this paper.

\section{CRediT authorship contribution statement}

R. Mangin: Conceptualization, Methodology, Investigation, Writing - review \& editing. H. Vahabi: Funding acquisition, Supervision, Conceptualization, Methodology, Validation, Writing review \& editing. R. Sonnier: Conceptualization, Methodology, Validation, Formal analysis, Writing - original draft. C. Chivas-Joly: Conceptualization, Methodology, Validation, Writing - review \& editing. J.-M. Lopez-Cuesta: Supervision, Conceptualization, Methodology, Validation, Writing - review \& editing. M. Cochez: Supervision, Conceptualization, Methodology, Validation, Writing review \& editing.

\section{Acknowledgements}

The authors wish to thank the Region Lorraine and IMT mines d'Alès for funding this work. They also thank the IUT de Moselle Est-"Plastinnov" technological platform and C2MA members for their technical assistance and discussion. The authors are grateful to their colleagues from LNE Fire department 522 for their advice and technical support.

\section{References}

[1] W. Chow, E. Teoh, J. Karger-Kocsis, Flame retarded poly(lactic acid): a review, Express Polym. Lett. 12 (2018) 396-417.

[2] B. Tawiah, B. Yu, B. Fei, Advances in flame retardant poly(lactic acid), Polymers 10 (2018) 876.

[3] R. Sonnier, A. Taguet, L. Ferry, JM. Lopez-Cuesta, Towards bio-based flame retardant polymers, Chapter 1 Flame Retardant Biobased Polymers, Springer Briefs in Materials, ed. Springer.

[4] H. Vahabi, F. Laoutid, E. Movahedifar, R. Khalili, N. Rahmati, C. Vagner, M. Cochez, L. Brison, F. Ducos, M. Reza Ganjali, M. Reza Saeb, Description of complementary actions of mineral and organic additives in thermoplastic polymer composites by flame retardancy index, Polym. Adv. Technol. 30 (2019) 2056-2066.

[5] H. Vahabi, R. Sonnier, B. Otazaghine, G. Le Saout, J.M. Lopez-Cuesta, Nanocomposites of polypropylene/polyamide 6 blends based on three different nanoclays: thermal stability and flame retardancy, Polymers 58 (2013) $350-360$.

[6] S. Pappalardo, P. Russo, D. Acierno, S. Rabe, B. Schartel, The synergistic effect of organicallymodified sepiolite in intumescent flame retardant polypropylene, Eur. Polym. J. 76 (2016) 196-207.

[7] R.L. Clough, Aging Effects on Fire-Retardant Additives in Organic Materials for Nuclear Plant Applications. Under Interagency Agreement DOE 40-550-75 NRC FIN No. A-1051, 1982.

[8] R.L. Clough, Aging effects on fire-retardant additives in polymers, J. Polym. Sci. Polym. Chem. Ed. 21 (1983) 767-780.

[9] M. Jimenez, S. Bellayer, B. Revel, S. Duquesne, S. Bourbigot, Comprehensive study of the influence of different aging scenarios on the fire protective behavior of an epoxy based intumescent coating, Ind. Eng. Chem. Res. 52 (2013) 729-743.

[10] U. Braun, V. Wachtendorf, A. Geburtig, H. Bahr, B. Schartel, Weathering resistance of halogen-free flame retardance in thermoplastics, Polym. Degrad. Stabil. 95 (2010) 2421-2429.

[11] H. Vahabi, R. Sonnier, L. Ferry, Effects of ageing on the fire behaviour of flameretarded polymers: a review, Polym. Int. 64 (2015) 313-328.

[12] N. Lesaffre, S. Bellayer, G. Fontaine, M. Jimenez, S. Bourbigot, Revealing the impact of ageing on a flame retarded PLA, Polym. Degrad. Stabil. 127 (2016) $88-97$.

[13] N. Lesaffre, S. Bellayer, H. Vezin, G. Fontaine, M. Jimenez, S. Bourbigot, Recent advances on the ageing of flame retarded PLA: effect of UV light and/or relative humidity, Polym. Degrad. Stabil. 139 (2017) 143-164.

[14] A. Beaugendre, C. Lemesle, S. Bellayer, S. Degoutin, S. Duquesne, M. Casetta, C. Pierlot, F. Jaime, T, Kim, M. Jimenez, Flame retardant and weathering resistant self-layering epoxy-silicone coatings for plastics, Prog. Org. Coating 136 (2019) 105269.

[15] J. Ni, L. Song, Y. Hu, P. Zhang, W. Xing, Preparation and characterization of microencapsulated ammonium polyphosphate with polyurethane shell by in situ polymerization and its flame retardance in polyurethane, Polym. Adv. Technol. 20 (2009) 999-1005.

[16] H. Ou, W. Wu, J. Hao, C. Wang, J. Xu, Inorganic-organic hybrid coatingencapsulated ammonium polyphosphate and its flame retardancy and water resistance in epoxy resin, Fire Mater. 38 (2014) 312-322.

[17] R. Mangin, H. Vahabi, R. Sonnier, C. Chivas-Joly, J.-M. Lopez-Cuesta, M. Cochez, Improving the resistance to hydrothermal ageing of flame-retarded PLA by incorporating miscible PMMA, Polym. Degrad. Stabil. 155 (2018) 52-66.

[18] E.W. Fischer, H.J. Sterzel, G. Wegner, Investigation of the structure of solution grown crystals of lactide copolymers by means of chemical reactions, KolloidZ. Z. Polym. 251 (1973) 980-990.

[19] F.P. La Mantia, M. Morreale, L. Botta, M.C. Mistretta, M. Ceraulo, R. Scaffaro, Degradation of polymer blends: a brief review, Polym. Degrad. Stabil. 145 (2017) 79-92.

[20] M. Gonzalez-Garzon, S. Shahbikian, M. Huneault, Properties and phase structure of melt-processed PLA/PMMA blends, J. Polym. Res. 25 (2018) $58-70$.

[21] J. Anakabe, A.M. Zaldua Huici, A. Eceiza, A. Arbelaiz, Melt blending of polylactide and poly(methyl methacrylate): thermal and mechanical properties 
and phase morphology characterization, J. Appl. Polym. Sci. 132 (2015) 42677-42684.

[22] G. Zhang, J. Zhang, S. Wang, D. Shen, Miscibility and phase structure of binary blends of polylactide and poly(methyl methacrylate), J. Polym. Sci. B Polym. Phys. 41 (2003) 23-30.

[23] A. Regazzi, S. Corn, P. Ienny, J.C. Bénézet, A. Bergeret, Reversible and irreversible changes in physical and mechanical properties of biocomposites during hydrothermal aging, Ind. Crop. Prod. 84 (2016) 358-365.

[24] K. Kamau-Devers, Z. Kortum, S. Miller, Hydrothermal aging of bio-based poly(lactic acid) (PLA) wood polymer composites: studies on sorption behaviour, morphology, and heat conductance, Construct. Build. Mater. 214 (2019) 290-302. 